\title{
CAREERS CLINIC
}

\section{What should doctors wear to work?}

\author{
Tweed, beautiful heels, Superman t shirts, or sensible coloured shirts? Opinions vary on what \\ doctors should wear at work, finds Abi Rimmer
}

\section{Abi Rimmer}

BMJ Careers

\section{"Appearances matter"}

Simon Fleming, immediate past president of British Orthopaedic Trainees' Association and specialist registrar in trauma and orthopaedics, says, "The question of what a doctor should wear has always been the start of a great argument. Should I wear a three piece suit, a white coat, or jeans? For that matter, should we cater to others'-patients' or colleagues'-unconscious biases? Ignoring the sartorial implications, what I wear to work is evidence to many of my training, my tribe, and, one could argue, my clinical competency.

"Daniel Webster Cathell's 1890 Book on the Physician Himself talks about how a doctor might demonstrate his competency. A lot of emphasis is placed on the quality of one's appearance (a suit) and accoutrements (a walking stick with a silver head). I would suggest not much has changed in how we demonstrate our professional, and to an extent personal, identity at work.

"We know that patients from Europe prefer a 'formal' look on their doctors, and prefer their surgeons, emergency doctors, and intensivists to be in scrubs. We know that we make snap, unconscious judgements about our colleagues, based on their appearance.

"Saying that, when I worked at Great Ormond Street Hospital I would sometimes wear my Superman t shirt and the children loved it. When I worked in Australia, a polo shirt in clinic was just fine.

"To the doctor wondering what to wear, I would say, wear what you can afford, what makes you comfortable (both inside and out), and what is appropriate to the job and patients. If I am in theatres all day, I go into work in jeans and a hoodie and get straight into scrubs; when I have clinic, it's a shirt, tie, and some tweed. That works for me. You do you."

\section{"Dress to inspire confidence"}

James S Thambyrajah, GP at Cheam Family Practice and First5 lead GP for Royal College of General Practitioners South West Thames Faculty, says, "I remember in my fourth year at medical school, I first began thinking about what to wear as a professional. I had an immense feeling of pride on being let loose on the wards for the first time. My biggest sartorial influence was, and still is, my father, an ENT surgeon. He advised me to wear 'sensible coloured shirts—blues, pinks, whites, and stripes.' He vetoed 'dark colours such as black, greys, and reds.'

"I adhere to the BMA dress code mantra of "dress in a manner which is likely to inspire public confidence.' For me this means wearing smart (and ironed) shirts and trousers.

"Patients are people at their most vulnerable-therefore I truly believe that first impressions are important. They want doctors to dress professionally - to instil in them that vital confidence boost. It shows that you take seriously the job of looking after someone.

"I also believe that job specifics define what you wear. Comfortable shoes are essential for long shifts in a hospital, for example. As a junior doctor doing paediatrics, I was told off by the night shift nurses for wearing leather shoes as I would make too much noise when walking or running onto the ward.

"When thinking about what to wear during my long days as a GP, I opt for comfortable, smart, and practical clothes. My choice of socks is the one personal and fun item-often unseen by others. I choose crazy multicoloured prints. To quote photographer Bill Cunningham, 'Fashion is the armour to survive everyday life."

\section{"Be your smart self"}

Clare Kane, specialty trainee year 7 haematology, Leeds, "My workday wardrobe has evolved over the years since I graduated. Together we have gone from cheap and cheerful Topshop tops and black trousers, via scrubs, black jeans (dark days indeed), to bright dresses, preferably with pockets.

"Now I choose clothes that are easy to clean, comfortable, and colourful: my patients are often in isolation rooms for weeks on end, so, hopefully, bright yellow flowers and butterflies brighten things up a little bit.

"I know there are dress codes out there, but I think the important thing is to be yourself (your smart self), and to wear something that you can do the work in. A dry-clean-only white skirt isn't going to be very practical on a night shift and grey jeggings are less suitable for a clinic.

"Shoes are obviously an important part of workwear, with flat shoes for long days, buckle shoes or lace ups for running on 
call, and, personally, I keep a ridiculous collection of beautiful heels for clinic days, but that is strictly optional.
"Oh, and for those of us who like skirts and dresses-in winter, if you have a paucity of pockets, get some wide legged boots, and ta dah you have an extra place for your bleeps, handover, phone, and pens. Sorted." 